\title{
Plataformas digitais na educação básica e os desdobramentos na formação do professor - a ágora para assimilação da cultura digital e promoção de práticas inovadoras
}

\author{
Ana Beatriz G. P. Carvalho ${ }^{1}$, Jaime C. S. Junior ${ }^{1}$ \\ ${ }^{1}$ Universidade Federal de Pernambuco (UFPE) \\ anabeatrizgpcegmail.com, jaime@cbvdigital.com.br
}

\begin{abstract}
This article aims to share a doctoral research that is still underway with the purpose of fostering collaborative community during the Brazilian Congress of Informatics in Education 2019. The article is formatted following the Postgraduate Students Experience (STUDX)
\end{abstract}

Resumo. Este artigo tem o objetivo de compartilhar uma pesquisa de doutorado que ainda está em curso com propósito de fomentar comunidade colaborativa durante o Congresso Brasileiro de Informática na Educação 2019. O artigo está formatado nos moldes do Postgraduate Students Experience (STUDX)

\section{A motivação}

Um estudo realizado pela National Research Council sobre as competências do século 21 esclarece que o aprendizado está voltado à capacidade de aplicar o que se aprendeu em situações novas. Segundo os resultados da pesquisa, as competências (para o século 21) estão divididas em três grandes domínios. O primeiro deles é denominado como cognitivo e abarca as estratégias e processos de aprendizado, criatividade, memória, pensamento crítico. Para os autores, "essa é a dimensão em que se tem uma oferta mais farta de pesquisas", porém, a pesquisa chama atenção sobre a existência de outros domínios que também exige importância para a formação do cidadão - o intrapessoal e o interpessoal. O intrapessoal tem relação com a capacidade de lidar com emoções e moldar comportamentos para atingir objetivos. Já o interpessoal envolve a habilidade de expressar ideias, interpretar e responder aos estímulos de outras pessoas.

Compreender as demandas do século XXI no contexto educacional brasileiro potencializa a responsabilidade das escolas em ofertar educação e formação alinhadas às iniciativas de intervir na sociedade. Isso implica em inovação pedagógica e esta discussão deve alcançar os programas de formação continuada do professorado. Em meio a era digital e ao cenário de inserção de tecnológicas nas escolas, aumenta a expectativa de promoção de práticas inovadoras, desde que estas sinalizem uma educação significativa e alinhada com as competências e habilidades esperadas para este século.

Este trabalho encontra motivação na crítica ao recorrente modelo de fomento de tecnologias nas escolas brasileiras. Em geral, o fomento de tecnologias educacionais não se pauta por um projeto pedagógico atento ao aspecto cultural das práticas inovadoras, tampouco é norteado pelos domínios das competências necessárias para a formação do indivíduo neste século (durante o seu percurso na educação básica). Ou 
seja, é mais rotativo, em termos de inserção de artefato tecnológico na escola, a entrega do artefato e a sugestão funcional de seu uso. Como não há uma preocupação com a construção cultural do uso dos artefatos por parte da comunidade escolar, é comum a reprodução do determinismo tecnológico que conduz, em primeira instância, o professor a reproduzir práticas tradicionais em detrimento às mudanças no agir pedagógico.

No que se refere às mudanças no agir pedagógico, é importante ressaltar que vivenciamos um contexto favorável às novas perspectivas de formação do professor. Já que integramos um cenário de bases estruturantes de uma nova dinâmica social e de uma nova ordem planetária: globalização, organizações aprendentes, inter/trans/ multidisciplinaridade, multiculturalismo, racionalidade comunicativa, pedagogia ciberespacial, dentre outros aportes que culminam em enredos e em processos emergentes no contexto do que Mattelart (2000) chama de sociedade informacional, e que Castells (1999) chama de sociedade em rede. Como tudo isso implica em novas formas de "pensar-agir", as escolas que ofertam educação básica são demandadas a adotar estratégias educacionais compatíveis com o atual contexto tecnológico, de maneira que seja possível redimensionar o papel do estudante, sugerindo atitudes de participação, criação, inovação e intervenção.

O surgimento de plataformas digitais que, em sua maioria, equipa a escola com conteúdos digitais, ferramentas para gestão pedagógica e funcionalidades de inteligência de dados têm ajudado a redesenhar a cultura escolar, de maneira a criar um cenário mais interativo e dinâmico. Atualmente, grandes empresas tem se dedicado a projetos dessa natura, a exemplo da Google e Microsoft. Este estudo tem como base a compreensão das possibilidades de mudança na cultura pedagógica provocada pela adesão das plataformas digitais a partir da compreensão da cultura digital. Mais precisamente, pretende-se perceber e problematizar a ideia de cultura digital e seus desdobramentos em práticas inovadoras. Logo, nesta proposta de pesquisa, espera-se (através de mensurações de dados qualitativos a partir de intervenções "in loco") uma resposta para o seguinte questionamento - Em que medida, a adesão de plataformas digitais pode impactar no ambiente escolar, de maneira a promover possibilidades de desenvolvimento e consolidação da cultura digital junto aos professores da educação básica?

Embora este estudo tenha como pilares as várias discussões já travadas no programa de pós-graduação EDUMATEC (UFPE) sobre Cultura Digital, suas identidades e conflitos, abarcando as perspectivas de inclusão digital e prática inovadora, a pesquisa está centrada na temática formação de professores para uso de tecnologias em educação. É preciso ressaltar que o engajamento da escola e, em especial dos professores, depende de como a organização e os atores são encaminhados à implementação e uso desses recursos. Sabattini (2017, p.16) explica que

na consideração da tecnologia educacional como um sistema sociotécnico, encontramos a dimensão axiológica, isto é, dos valores incorporados pelos agentes a uma determinada tecnologia. Mas além dos valores, os sistemas técnicos incorporam um grande número de conteúdos culturais, devido à presença dos agentes humanos como parte constituinte, com especial destaque para os conhecimentos ou representações que estes possuem a respeito dos próprios componentes, estrutura e funcionamento do sistema. Dessa forma, uma dada inovação tecnológica não terá os efeitos desejados, a não ser que as dimensões 
VIII Congresso Brasileiro de Informática na Educação (CBIE 2019)

Anais dos Workshops do VIII Congresso Brasileiro de Informática na Educação (WCBIE 2019)

culturais e políticas sejam propícias para absorvê-las e incorporá-las. Este fato se faz patente no que diz respeito à cultura organizacional e, especificamente, à cultura escolar.

Um dado relevante é que o Governo do Estado de Pernambuco e da Paraíba, através de suas respectivas secretarias de educação firmaram convênio com o programa Google for Education. Tal convênio prevê a disponibilização da plataforma Google e consequentemente trará às escolas públicas a possibilidade de disseminar novas estratégias advindas do avanço tecnológico e da consolidação da sociedade da informação. Assmann (2000, p. 7) chama atenção ao aspecto da aprendizagem nesse contexto de inserção tecnológica:

No tocante à aprendizagem e ao conhecimento, chegamos a uma transformação sem precedentes das ecologias cognitivas, tanto das internas da escola, como das que lhe são externas, mas que interferem profundamente nela. As novas tecnologias não substituirão o/a professor/ a, nem diminuirão o esforço disciplinado do estudo. Elas, porém, ajudam a intensificar o pensamento complexo, interativo e transversal, criando novas chances para a sensibilidade solidária no interior das próprias formas do conhecimento.

É nesse cenário em que os atores da educação são norteados a aderir aos princípios da cultura digital em favor de seus objetivos pedagógicos. Para os pesquisadores Santana e Amadeu (2011), o conceito de cultura digital abarca os seguintes significados:

Reunindo ciência e cultura, antes separadas pela dinâmica das sociedades industriais, centrada na digitalização crescente de toda a produção simbólica da humanidade, forjada na elação ambivalente entre o espaço e o ciberespaço, na alta velocidade das redes informacionais, no ideal de interatividade e de liberdade recombinante, nas práticas de simulação, na obra inacabada e em inteligências coletivas, a cultura digital é uma realidade de uma mudança de era. Como toda mudança, seu sentido está em disputa, sua aparência caótica não pode esconder seu sistema, mas seus processos, cada vez mais auto-organizados e emergentes, horizontais, formados como descontinuidades articuladas, podem ser assumidos pelas comunidades locais, em seu caminho de virtualização, para ampliar sua fala, seus costumes e seus interesses. A cultura digital é a cultura da contemporaneidade.

Sendo assim, considerar a possibilidade de envolvimento com a cultura digital como consequência da adesão de artefatos, da reorganização da técnica e da idealização de procedimentos tecnológicos pode favorecer os processos do ensino e garantir efetividade e criatividade no processo de aprendizagem. Ademais, o cenário de adesão significativa das plataformas digitais, em especial na educação pública, atribui a esta pesquisa uma oportunidade de contribuição social e pedagógica com desdobramentos na formação continuada do professor.

\section{A metodologia e os resultados esperados}

A metodologia se materializa em procedimentos alinhados ao problema e objetivos da pesquisa e, neste trabalho, ela lança-se na investigação sobre a identificação de uma possível ecologia cognitiva que impacta a comunidade escolar, em especial no corpo 
VIII Congresso Brasileiro de Informática na Educação (CBIE 2019)

Anais dos Workshops do VIII Congresso Brasileiro de Informática na Educação (WCBIE 2019)

docente a partir da implantação de plataformas digitais na escola. Considerando que este trabalho tem como imperativo metodológico os estudos culturais, a pesquisa se nutre de procedimentos originários das ciências sociais aplicadas, bem como da pedagogia enquanto aportes teóricos, mas sobretudo metodológicos. No Infográfico 1, está organizado o percurso metodológico com o problema e o objetivo geral desta pesquisa, no qual é possível compreender a tipologia, a arquitetura, a natureza e finalidade. Já no Infográfico 2, é possível associal o percurso metodológico aos resultados esperados em detrimento dos aportes teóricos investidos na pesquisa.

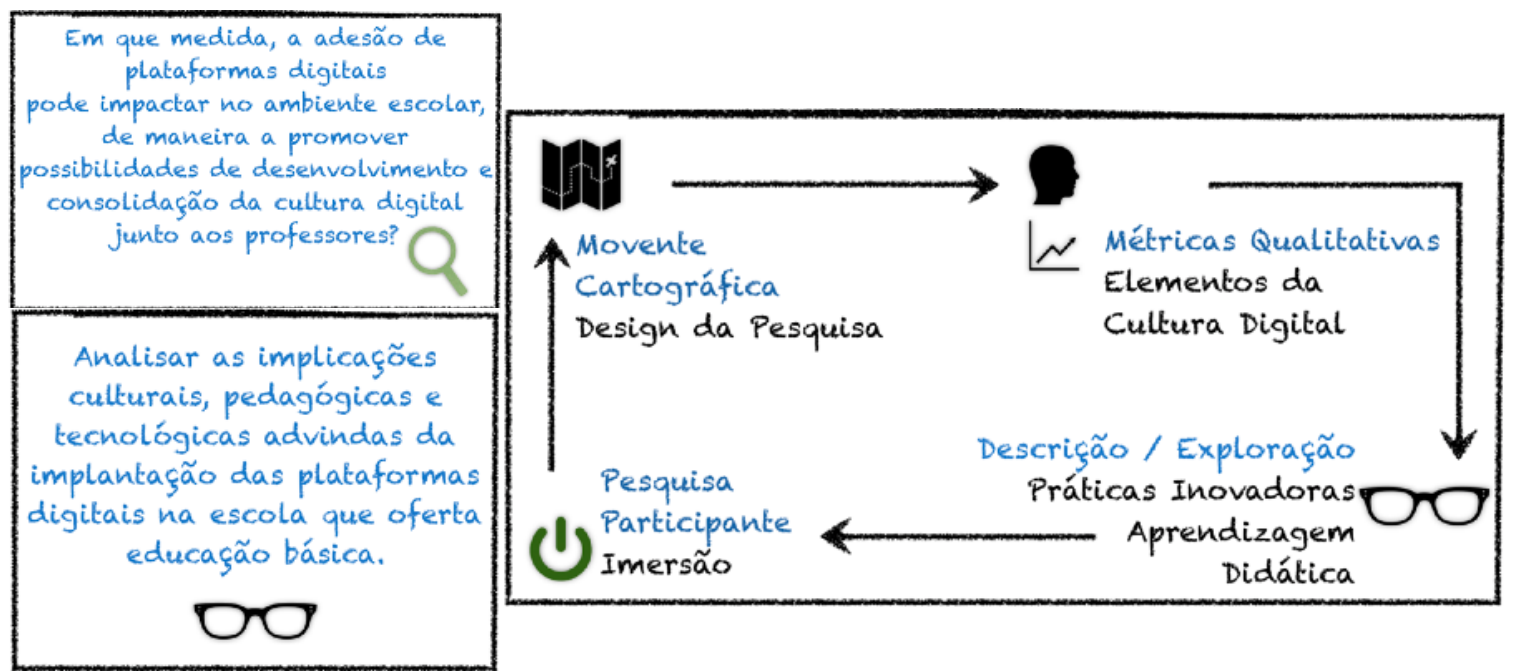

Infográfico 1. Percurso Metodológico

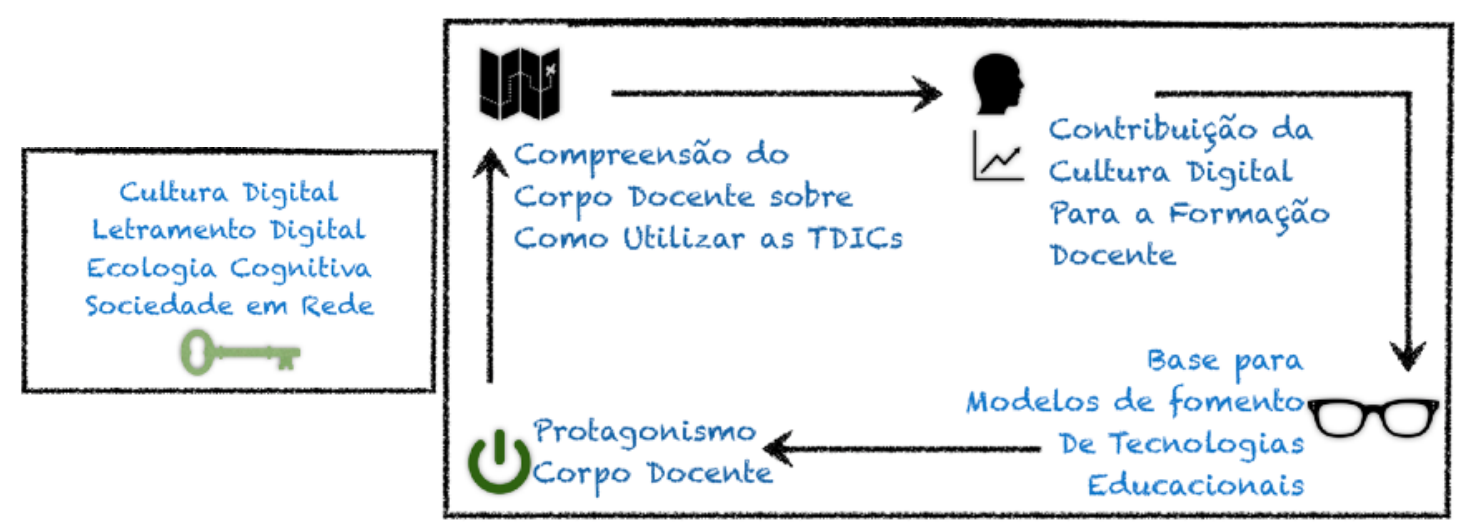

Infográfico 2. Percurso Metodológico

\section{As contribuições e os predicativos da pesquisa}

$\mathrm{O}$ aspecto de originalidade nesta pesquisa reside na relação estabelecida entre a reflexão sobre cultura digital, campo advindo dos estudos culturais, que, neste estudo, se adequa às demandas das novas perspectivas da formação docente e também estabelece relação com as práticas pedagógicas que sinalizam indícios de inovação no processo de ensino e aprendizagem. Em termos de contribuições para os estudos sobre educação tecnológica, a pesquisa adota uma condução multidisciplinar que potencializa os laços entre os estudos desenvolvidos pelas áreas de comunicação e educação. Neste caso, lança-se o 
VIII Congresso Brasileiro de Informática na Educação (CBIE 2019)

Anais dos Workshops do VIII Congresso Brasileiro de Informática na Educação (WCBIE 2019)

olhar sistemático da ciência para desvendar novos procedimentos para compreender a educação tecnológica.

Considerando o contexto de recorrente disponibilização de artefatos tecnológicos nas escolas brasileiras (em especial as escolas públicas), a pesquisa se detém às plataformas digitais enquanto aporte de tecnologia que demanda investigação sobre os desdobramentos culturais e pedagógicos. A pesquisa já dispõe de dados que revela uma presença significativa de plataformas digitais na unidades escolares, a exemplo do projeto Google for Education que, uma vez implantada, disponibiliza novos caminhos para a gestão escolar, pedagógica e tecnológica. Em termos de possibilidades de novas discussões, espera-se que a pesquisa permita novos horizontes de formação docente, bem como sinalizadores de modelos de fomento de aportes tecnológicos, fato que favorece às políticas públicas.

\section{Referências}

AMADEU, Sérgio; SANTANA, Bianca. Cultura Digital. Site de discussão sobre cultura digital. Disponível em: < http://culturadigital.br/conceito-de-cultura-digital/>. Acesso em: 24 jul. 2016.

ASSMANN, Hugo. Reencantar a Educação: Rumo à sociedade aprendente. Petrópolis: Vozes, 2012.

AUGÉ, Marc. Sobremodernidade: do mundo tecnológico de hoje ao desafio essencial do amanhã. In: MORAES, Denis de (org.). Sociedade midiatizada. Rio de Janeiro: Mauad, 2006.

BERNHEIM, Carlos Tünnerman; CHAUÍ, Marilena. Desafios da universidade na sociedade do conhecimento. Brasília: UNESCO, 2008. p. 7-27.

BOURDIEU, Pierre. A Escola conservadora: as desigualdades frente à escola e à cultura. In: NOGUEIRA, Maria Alice; CATANI, Afrânio. Escritos de Educação. Petrópolis, RJ: Vozes, 1998. Capítulo II.

CASTELLS, Manuel. A era da informação: economia, sociedade e cultura. São Paulo: Paz e terra, 1999

CARVALHO, A. B. G.; ALVES, T. P. Práticas e percursos dos professores da Educação Básica com ações de autoria e colaboração nas redes sociais. Rev. Diálogo Educ., Curi ba, v. 15, n. 45, p. 493-514, maio/ago. 2015

FREIRE, Paulo. Pedagogia do Oprimido. São Paulo: Paz e terra, 2014. GIL, Antônio Carlos. Como elaborar projetos de pesquisa. São Paulo: Atlas. 2007

HARVEY, David. A condição pós-moderna. 8.ed. São Paulo: Loyola, 1999. Parte I, capítulo 2 - Modernidade e Modernismo.

LEMOS, André. Ciberespaço e Tecnologias Móveis. Processos de Territorialização e Desterritorialização na Cibercultura. 2007. Disponível em: http:// www.facom.ufba.br/ciberpesquisa/andrelemos/territorio.pdf

LÉVY, Pierre. A revolução contemporânea em matéria de comunicação. In: MARTINS, Francisco Menezes; SILVA, Juremir Machado da. Para navegar no século XXI. Tecnologias do imaginário e cibercultura. 3.ed. Porto Alegre: Sulina/Edipucrs, 2003. 